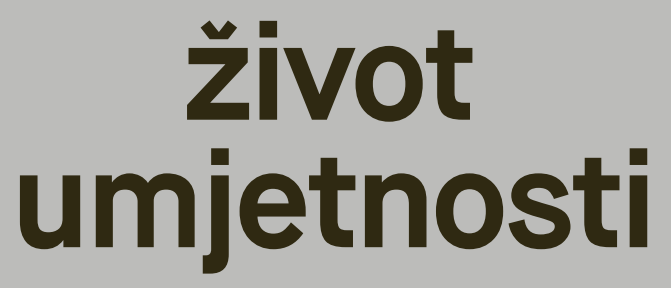









\section{MADELEINE, MADELEINE I MADELEINE}

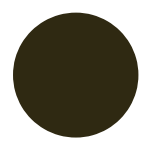

Vlado Kristl, Madeleine, Madeleine,

Cité internationale des arts, Pariz, 14. veljače -2. ožujka 2020.

DOI: 10.31664/zu.2020.106.11

Nakon smrti slikara, pjesnika i filmskog autora Vlade Kristla 7. srpnja 2004., održano je nekoliko izložbi posvećenih njegovu opusu. U godini smrti galerija Dany Keller u Münchenu postavlja izložbu od nazivom Kratko vrijeme... dugo, a galerija Rigo u Novigradu Vlado Kristl: Kraj poretka. U Umjetničkom paviljonu u Zagrebu 2007. godine predstavljena je izložba Prije egzila-radovi od 1943. do 1962. Zatim ponovno u galeriji Dany Keller Vlado Kristl: slike i crteži 2008., u Muzeju moderne i suvremene umjetnosti u Rijeci 2011. izložba Vlado Kristl, a u galeriji Adris u Rovinju 2014. godine. Posljednja je u ovom nizu izložba Madeleine, Madeleine, održana u Parizu u galeriji Cité internationale des arts od 14. veljače do 2. ožujka ove godine.

Zanimanje za ovoga intrigantnog i nedovoljno istraženog autora ne posustaje, i to ne samo na području slikarstva; njegov je i filmski i književni opus često u fokusu teoretičara i prevoditelja. Potvrda je tome i ovogodišnje predstavljanje umjetničkog rada Vlade Kristla francuskoj publici, u organizaciji udruženja AMCAParis, ${ }^{1}$ a u suradnji s novigradskim Muzejom Lapidarium te Ministarstvom kulture i Ministarstvom vanjskih i europskih poslova Republike Hrvatske. Radovi Vlade Kristla predstavljeni su kroz tri segmenta-izložbu slika Madeleine, Madeleine koju kustoski potpisuje Jerica Ziherl, promociju dvojezične knjige poezije Stojim u beskraju u prijevodu Martine Kramer (izdavač L'Ollave) te filmski program u Goethe-Institutu pod vodstvom Branke Benčić i Chrisa Dercona.
Almae Matris Croaticae Alumni (AMCA-Paris) udruženje je intelektualaca, bivših studenata hrvatskih sveučilišta, koje od I99I. godine kontinuirano radi na promociji hrvatske kulture u Francuskoj.

\section{Ana Marija Habjan}

Samostalna istraživačica, Zagreb 
I dok pjesnička zbirka i izbor filmova nude uvid u radove ovog umjetnika nastale prije sedamdesetih godina prošloga stoljeća (s iznimkom samo jednog kratkog filma ponuđenog u francuskoj retrospektivi-Svjetski kongres beskućnika iz 2003., koji je ujedno posljednji Kristlov film), izložba Madeleine, Madeleine obuhvaća slike, grafike i knjige umjetnika nastale u vremenskom rasponu od sredine sedamdesetih pa do smrti 2004. godine. Ovu vremensku odrednicu treba međutim uzeti s rezervom; Kristl je, naime, često svoje slike preslikavao i iznova na starima stvarao nove. Od izloženih slika nekoliko je takvih koje je započeo još sedamdesetih (Susanne u kupaonici, 1974.-2002; Buket cvijeća/Uhićenje Ulrike Meinhof, 1975.), ali većinu ih je naslikao u posljednjem desetljeću života. Upravo je zato Madeleine, Madeleine značajna izložba, jedna od rijetkih kojoj je središte zanimanja na onom dijelu Kristlova stvaralaštva o kojem znamo najmanje.

Kristlove slike iz „njemačkog perioda”, razdoblja nakon odlaska iz domovine u Njemačku 1963. godine, često su bile predmetom rasprava. U potpunoj suprotnosti od onoga što je slikao ranije, dok je istraživao mogućnosti apstraktnoga likovnog jezika te bio sudionikom avangardnih umjetničkih kretanja u ondašnjem Zagrebu, slike nastale nakon dobrovoljnog egzila (koji je trajao puna četiri desetljeća!) figurativne su po mogućnosti prepoznavanja određenih motiva koji se ponavljaju, ekspresionističke po snažnoj i slobodnoj gesti, s velikim plohama jakih boja, te procesualne po vidljivim slojevima namaza i linija nastalih u različitim fazama. Nisu naišle na preveliko razumijevanje ni njemačke publike ni hrvatskih pratitelja njegova rada. Prvima je bio zanimljiviji kao filmski autor koji je na sceni već postigao slavu osebujnim autorskim izrazom i originalnim eksperimentima, a na tržištu umjetnina prednost su imali radovi drugačijih koncepata. Drugi nisu mogli prežaliti njegovu egzatovsku i minimalističku fazu te su priželjkivali da se slikar vrati provjerenom sistemu. Ova Kristlova djela nisu završila ni u njemačkim ni u hrvatskim muzejima. A i rijetki su bili kolekcionari koji su ih kupovali pa je većina tih djela danas u privatnom vlasništvu, u krugu bliskih prijatelja te obitelji.

Kustosica izložbe, povjesničarka umjetnosti Jerica Ziherl, kojoj je ovo već treća izložba u kojoj se bavi Kristlovim opusom, za pariško predstavljanje odabrala je šezdesetak Kristlovih djela u vlasništvu umjetnikove kćeri Madeleine, koja od početka devedesetih živi u Parizu. Uglavnom su to ulja na platnu, nekoliko grafika, a unutar vitrina izložena je i serija slika malih formata. Kao popratni materijal koji oslikava svestranost ovoga nekonvencionalnog autora, također u vitrinama, izložen je izbor autorskih izdanja koja je Kristl redovito objavljivao te nekoliko pisama (od kojih se izdvaja i nudi na čitanje ono adresirano na Radovana Ivšića). Unutar postava samo je jedan animirani film, i to jedan od prvih koje je radio za Zagreb film, Šagrenska koža iz 1960. godine (koji predstavlja određeni kuriozum jer i stilski i vremenski pripada prvom razdoblju Kristlova stvaralaštva), a na zidovima izložbenog prostora zalijepljeni su ulomci Kristlovih stihova koji se slobodnim asocijacijama vežu uz slike. Autoričina intencija bila je pokazati Kristlovu raznorodnost, svijet u kojem funkcionira i kao slikar, crtač i animator, kao pjesnik i pisac te kao izdavač i dizajner. Jednako tako, namjera je bila i dovesti ga u vezu s gradom u kojem je izložba održana, barem kroz za samu izložbu irelevantne činjenice, pa su tako među pismima tri imena povezana s pariškom umjetničkom scenom (Braco Dimitrijević, Ivan Picelj i Radovan Ivšić), a predložak za animirani film poznata je priča francuskog književnika Honoréa de Balzaca.

U pismu pariškom prijatelju Ivšiću od 24. siječnja 1973., uz koje mu šalje i nekoliko svojih objavljenih knjižica i tekstova, Kristl piše: „Možda si igdje vidio te moje knjižice. Za anarhiju su napravljene. Imaju samo analitički i istraživački karakter. Traženje, šta bi moralo biti, da bi se omogućilo nešta dalje ići iz stanja bogatstva i siromaštva, nego šta nam to obećavaju „socijalne" revolucije. Nema parola. Samo mirisanje, njušenje, slušanje, oprez, pokušaji usavršavanja forme produkcije, anarhistične produkcije.// Pozdrav, ostaj mi pjesnik, umjetnik.// Veselim se da znam, 
da radiš na stvarima koje usrećuju duh i razum, jednakom upornošću, izdržljivošću, kao uvijek. Tu si, istina reći, sam, ali i jedini na svijetu, svagdje drugdje si jedan broj, jedan od mnogih, za koji položaj se naše duše zbilja ne otimaju."

Ovaj ulomak možda najbolje oslikava Kristlov način razmišljanja primjenjiv na cjelokupan njegov rad i ključ je za čitanje i njegovih slika. Kristl istražuje sam, a ne tamo gdje je već uspostavljen sistem i gdje je jedan od mnogih. Upravo zato, uostalom, i napušta geometriju, apstrakciju i enformel smatrajući da su to postali modni stilovi. Izložena ulja na platnu većinom su, barem uvjetno rečeno, portreti, krajolici i nekoliko mrtvih priroda. Najčešći je motiv ženski lik. Njegovi modeli poziraju, naslonjeni na stol, u fotelji ili stoje uspravni, kao tijekom sata crtanja. Figure su smještene u gotovo potpuno apstraktnim ambijentima; prostor, ako je naznačen, virtuozno je skiciran linijama poda, velikih stolova ili rešetaka prozora. Istodobno, potez kistom odaje veliku vještinu, pa i užitak u samom činu slikanja, u ljepoti boje i linije.

Koliko god tema bila čitljiva, kroz elegantne i vitke ženske likove i kroz naslove slika koje često nose ženska imena te unatoč naizgled benignom sadržaju koji se na prvi pogled nudi, Kristlove slike na konotacijskoj razini nose i neka druga značenja koja pobuđuju nemir i nelagodu, a ukupni je dojam kojim zrače prijeteći. Lica figura prekrivena su oblakom, velom ili crnom mrljom, a pojedine plohe potpuno zasićene brojnim i gustim premazima boje. Otkriveni dijelovi tijela-naslikane usne, bradavice dojki ili noge, naglašavaju putenost. Kao da prisustvujemo nekom trenutku pred oluju ili smo svjedoci nekog čina strasti.

Tko su Anouchka, Sandra Nettelbeck, Judith Walgenbach, Gospođa kraljica dvorca, Johanna, Claudia, Julia, Lilli Thalgott? Stvarne žene, poznanice, umjetnice, redateljice, iz života, svijeta filma ili Umjetničke akademije u Hamburgu, gdje je predavao od 1979. do 1996. godine? Žene su glavna tema Kristlova slikarstva u kasnijim razdobljima, nadahnuće su za vječnu težnju dosezanja ideala ljepote. Svjestan zamki koje ta težnja sa sobom nosi, kao i mogućnost uklapanja u neki novi definirani sistem, Kristl dovodi sliku do, takoreći, ruba kiča, do negacije i destrukcije prikaza motiva. Poigravajući se s klasičnim štafelajnim slikarstvom ispituje granice, dijelove platna ostavlja neoslikanima (Moja kći Madeleine u Parizu, 1995.), kombinira snažan potez kista i liniju (Judith Walgenbach, 2000.), kao podlogu upotrebljava pronađenu sliku (Wilhelm Claudius, 1999.) ili pak svoju vlastitu (Uhićenje Ulrike Meinhof, 1975.), koje djelomično i potpuno preslikava, ili pak izrezane oblike od papira dodaje ulju na platnu kao kolaž (Ponovno oslikan zastor, 1996.-1999.). U seriji slika manjih formata $28 \times 31 \mathrm{~cm}$, s raskošnim porculanskim okvirima, namjerno prevelikima u odnosu na samu „sliku” u središtu, okvir tretira jednako slikarski, pa i njega oslikava (Bez naziva, 1978., 1982.-1986.).

Ženski lik kao alegorija slikarstva, s kistom u ruci kao atributom slikarske vještine, pojavljuje se na dvije slike: Posljednji klon, 2000. i Smrt umjetnosti, 2001. U Posljednjem klonu ženski akt drži kist naslonjen na plohu platna ili papira ispred sebe. Ne vidi što slika jer joj oči prekriva veo. Ispod vela proviruju usne, a iznad visoka skupljena tamna kosa. Gotovo cijelu pozadinu slike prekrivaju široke žute daske poda, a visoko pri vrhu kadra, uz dio zida, smješten je stol nacrtan u nekoliko brzih poteza. Koji je sadržaj ove slike? Da je slikarstvo kopirajući samo sebe došlo do kraja u nemogućnosti stvaranja ičega novoga? U Smrti umjetnosti uz ženski lik pojavljuje se iz tame još jedna ruka, muška, s paletom, još jednim slikarskim atributom, koja kao da je izronila iz mraka koji je stvorio sam kist.

Izložba Madeleine, Madeleine ukazala je još jednom na potencijal i potrebu preispitivanja i analize Kristlova slikarstva nakon šezdesetih. Iza motiva krhkih ženskih figura, vaza i cvijeća, mačaka i krajolika, krije se neukrotiva pjesnička narav slikara Kristla, buntovni karakter umjetnika koji je obilježio cjelokupan njegov život.

Na kraju treba reći i da je naziv izložbe jednak nazivu kratkometražnoga igranog filma u boji koji Kristl radi u Münchenu 1963., na početku svoje njemačke filmske 


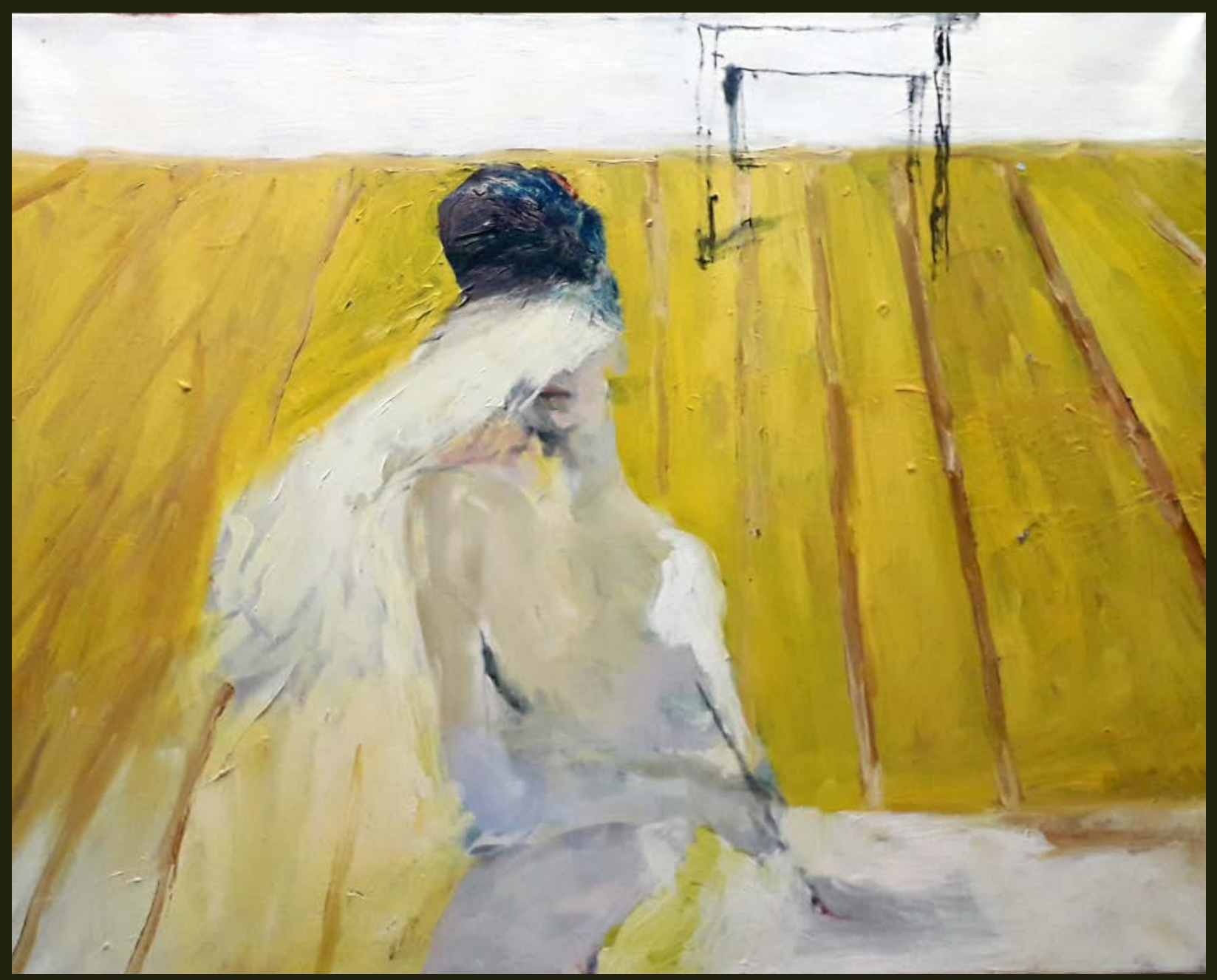




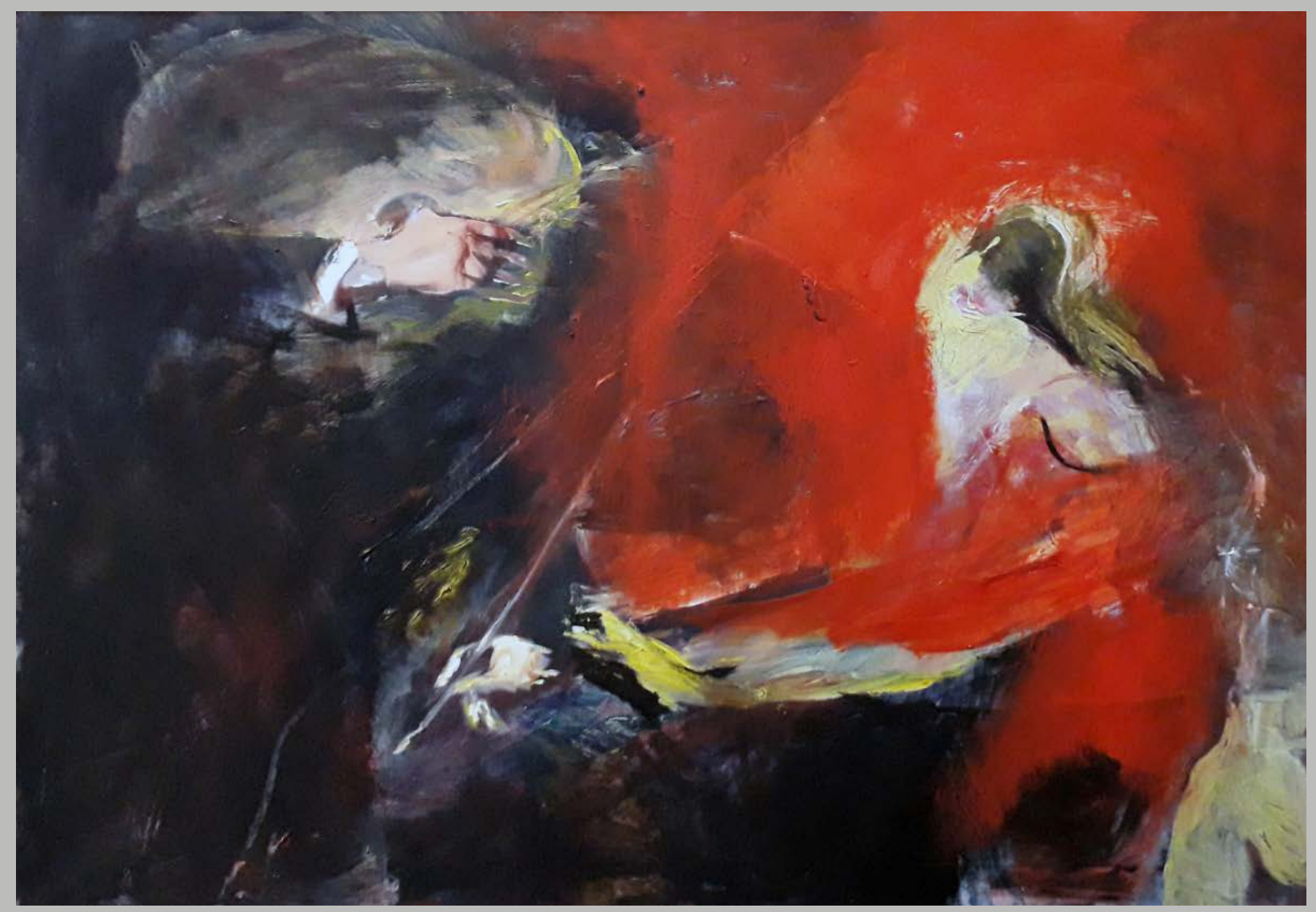


karijere. Madeleine, Madeleine ${ }^{2}$ desetominutna je ljubavna priča, smještena u gradskom parku s teniskim terenom jednog proljetnog dana s oscilacijama od sunčanog neba do proloma oblaka. Vremenske promjene prate i one emocionalne glavnih junaka. Načinom snimanja, primjenom ekstremnih planova, montažnim rezovima i ponavljanjem scena Kristl je stvorio malo poetsko remek-djelo. No ne bez sukoba s producentom i ostalom filmskom ekipom s kojom se razišao odmah nakon snimanja. Glavna glumica, lijepa Madeleine, kći poznatog njemačkog pisca i novinara Siegfrieda Sommera, nije bila profesionalna glumica. Nakon ovog snimanja više se nikada nije bavila glumom, ali je uspomena na nju ostala kao svojevrsni simbol sretne i zaljubljive mladosti. Tri godine kasnije Vlado i njegova supruga Jelena dobili su kćer, koju su nazvali Madeleine.
2

Madeleine, Madeleine, I963., kratkometražni igrani film u boji, $35 \mathrm{~mm}$, Io min, producent Rob Houwer, München. 

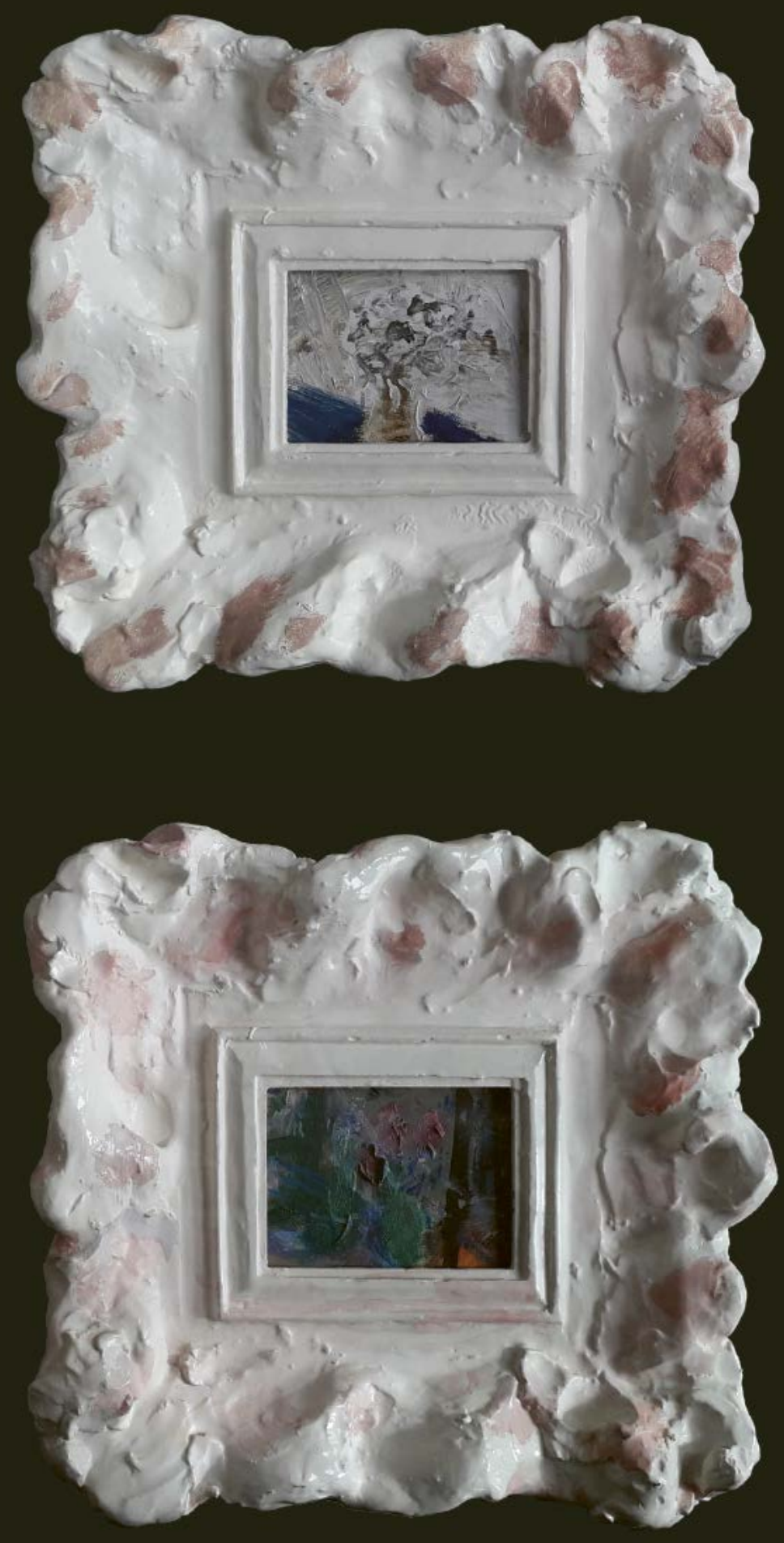